\title{
Effect of Gamma Rays on Non-basmati Aromatic Rice in $\mathbf{M}_{\mathbf{1}}$ Generation
}

\author{
Zafar Imam* and Nihar Ranjan Chakraborty
}

\author{
Department of Genetics \& Plant Breeding and Crop Physiology, Palli Siksha \\ Bhavana(Institute of Agriculture), Visva-Bharati, Sriniketan-731236
}

*Corresponding author

\section{A B S T R A C T}

\begin{tabular}{|l|}
\hline Ke y w o r d s \\
Mutation, Gamma \\
$\begin{array}{l}\text { Rays, Aromatic } \\
\text { rice, } \mathrm{M}_{1} \text { generation }\end{array}$ \\
\hline Article Info \\
\hline $\begin{array}{l}\text { Accepted: } \\
\text { 26 July } 2018 \\
\text { Available Online: } \\
\text { 10 August } 2018\end{array}$ \\
\hline
\end{tabular}

Keywords

Mutation, Gamma

Rays, Aromatic rice, $\mathrm{M}_{1}$ generation

\section{Introduction}

Rice is nutritious and rich in groups of vitamin $\mathrm{B}$, with almost no cholesterol. On the basis of aroma content, rice cultivars are classified as aromatic and non-aromatic genotypes. Many non-basmati traditional aromatic rice cultivars are famous due to their excellent grain quality and aroma. Aroma in scented rice depends on the amount of 2 acetyl-1-pyrroline (2AP).

But traditional aromatic rice cultivars are crippled by low yield potential, late maturity
Effect of 250Gy, 300Gy, 350Gy and 400Gy gamma rays on Badsabhog, popular nonbasmati aromatic landraces of West Bengal was studied in $\mathbf{M}_{1}$ generation under field condition. In general, plant height, number of total tillers, effective tillers plant- ${ }^{1}$, panicle

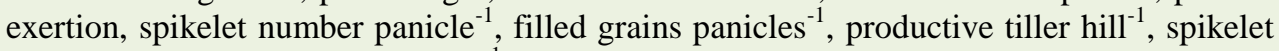
fertility (\%), and grain yield plant $^{-1}$ decreased with increase in dose at variable rate due to negative effect of mutation. Total tiller hill ${ }^{-1}$, Primary branch panicle ${ }^{-1}$ and Secondary branches panicle ${ }^{-1}$ were increased in all the irradiated population over control, which might be due to stimulatory effect of mutagen. The results indicated the differential sensitivity of the genotypes and characters to radiation treatment. The overall results indicated that spikelet fertility percentage (\%) was more sensitive to gamma irradiation as compared to other yield attributing characters in non-basmati aromatic rice. 
its component characters through hybridization and recombination becomes difficult. Therefore, generation of variability through mutagenic treatments is of paramount importance for improvement of this crop.

Gamma ray is one of the potent mutagens which can be used in rice breeding. Many attempts in the field of mutation research have been made by different scientists to get desirable traits in cultivated rice and in determining the most effective mutagenic treatment (Reddy and Rao 1988, Bansal et al., 1990, Pillai et al., 1993).

The present investigation was conducted to study the effects of $\gamma$-rays in $\mathrm{M}_{1}$ generation on dry seeds of non-basmati aromatic rice variety, Badsabhog.

\section{Materials and Methods}

Dry, uniform, bold seeds of variety Badsabhog each weighing $250 \mathrm{~g}$ were taken in five packets for the experiment. Four packets were used for gamma irradiations. The seeds were placed in single layer inside the radiation chamber to get the seeds irradiated. The seeds were irradiated with four different doses of gamma rays viz. 250Gy, 300Gy, 350Gy and 400Gy (1Gray = 1 joule per kg of matter undergoing radiations $=0.1 \mathrm{kR}$ ) from 60Co source at Bidhan Chandra Krishi Viswavidyalaya (BCKV), West Bengal. The remaining unexposed seed packet was used as control. Seeds from each treatment combination were sown immediately in the seedbed separately. Thirty-day-old seedlings from each treatment along with control were transplanted @ one seedling per hill in puddled field following ten rows plot with row length was $3.0 \mathrm{~m}$. Row to row and plant to plant distances $30 \mathrm{~cm}$ and $15 \mathrm{~cm}$ were kept, respectively The main tillers of suspected mutant plants were bagged just before flowering. Standard cultural practices were followed to raise a good healthy crop.
Observations on pre and post-harvest characters of $\mathrm{M}_{1}$ individual plants from each treatment were taken. Observations were recorded for plant height $(\mathrm{cm})$, panicle length (cm), number of tillers and effective tillers plant- ${ }^{1}$ were recorded before harvesting whereas, no. of primary branches panicle ${ }^{-1}$, no. of secondary branches panicle ${ }^{-1}$, no. of total branches panicle ${ }^{-1}$, filled grains, chaffy grains, total grain, spikelet fertility and grain yield plant- ${ }^{-}$was recorded after harvesting.

\section{Results and Discussion}

Effect of gamma irradiation on non-basmati aromatic rice was studied in $\mathbf{M}_{1}$ generation under field condition. The mean performances in respect of various quantitative characters in $\mathrm{M}_{1}$ populations are presented in Table below.

\section{Plant height (cm)}

Minimum and maximum mean values for plant height in non-basmati aromatic rice varied from 400 Gy (136.26) to control (153.27). The highest (127-177) and lowest (136-172) range was recorded in $250 \mathrm{~Gy}$ and control. The maximum $\mathrm{CV}$ was recorded in 350 Gy (6.94) and lowest for control (4.27) (Table 1).

Reduction of plant height was more with increase in doses. This result are in agreement with Cheema and Atta (2003), Chakraborty and Kole (2008), Efendi et al (2017). Sasikala and Kalaiyarasi, (2010) reported that plant height was drastically reduced at the dose of 100Gy and 200Gy in all the six varieties due to radiation treatment. Decreasing effects in the above characters might be due to physiological damage caused by mutagen at higher doses. Interruption in DNA synthesis and other physiological and biochemical changes after mutagenic treatment may lead to reduction of plant height. 


\section{Panicle exsertion (cm)}

Minimum and maximum mean values for Panicle exsertion in non-basmati aromatic rice varied from $400 \mathrm{~Gy}$ (12.16) to control (16.87). The highest (1.00-21.20) and lowest (11.50-21.00) range was recorded in $300 \mathrm{~Gy}$ and control. The maximum CV was recorded in 400 Gy (36.58) and lowest for control (11.26) (Table-1). Higher doses of gamma rays brought about more reduction in Panicle Exsertion.

\section{Total tiller hill ${ }^{-1}$ and productive tiller hill ${ }^{-1}$}

Minimum and maximum mean values for Total tiller hill ${ }^{-1}$ in non-basmati aromatic rice varied from 350 Gy (12.94) to $250 \mathrm{~Gy}$ (15.90). The highest (36-6) and lowest (22-4) range was recorded in $300 \mathrm{~Gy}$ and $400 \mathrm{~Gy}$. The maximum $\mathrm{CV}$ was recorded in $400 \mathrm{~Gy}$ (37.31) and lowest for control (25.27).

Minimum and maximum mean values for Productive tiller hilll ${ }^{-1}$ in non-basmati aromatic rice varied from 350 Gy (7.42) to control (13.30). The highest (3-22) and lowest (3-16) range was recorded in $300 \mathrm{~Gy}$ and $350 \mathrm{~Gy}$. The maximum $\mathrm{CV}$ was recorded in $400 \mathrm{~Gy}$ (47.88) and lowest for control (24.37) (Table 2).

Similar observation reported by Chakravarti et al., (2013) the mutagenic treatments caused significant decline in Effective tiller per hill in all the treatments of the genotypes. But in treatment 40kR gamma-ray and $30 \mathrm{KR}$ gamma ray it was high. Harding et al., (2012) observed that in irradiated plants of $\mathrm{M}_{1}$ generation increase in gamma ray doses from 50 to $300 \mathrm{~Gy}$ had little or no effect on tiller production as there were no significant differences in tiller number of irradiated seeds and non-irradiated (control) for all the varieties evaluated.
Flag leaf area $\left(\mathrm{cm}^{2}\right)$ and Panicle Length (cm)

Minimum and maximum mean values for Flag leaf area in non-basmati aromatic rice varied from control (16.59) to 250 Gy (18.90). The highest (7.50-33.15) and lowest (11.85-24.75) range was recorded in control and $350 \mathrm{~Gy}$. The maximum CV was recorded in control (29.28) and lowest for $350 \mathrm{~Gy}$ (17.58).

Minimum and maximum mean values for Panicle length in non-basmati aromatic rice varied from 400 Gy (25.21) to control (27.26). The highest (10.00-31.00) and lowest (21.00-29.50) range was recorded in 400 Gy and $250 \mathrm{~Gy}$. The maximum CV was recorded in 400 Gy (15.10) and lowest for $250 \mathrm{~Gy}$ (6.96) (Table 3).

\section{Primary branch panicle ${ }^{-1}$ and Secondary branches panicle ${ }^{-1}$}

Minimum and maximum mean values for Primary branch panicle ${ }^{-1}$ in non-basmati aromatic rice varied from 350 Gy (7.78) to 300 Gy (8.65). The highest (5.00-12.66) and lowest (5.66-9.66) range was recorded in 250 Gy and 350 Gy. The maximum CV was recorded in 250 Gy (17.06) and lowest for 300 Gy (11.75).

Minimum and maximum mean values for Secondary branches panicle ${ }^{-1}$ in non-basmati aromatic rice varied from $350 \mathrm{~Gy}$ (24.05) to 300 Gy (28.90). The highest (12.33-55.33) and lowest (13.33-34.00) range was recorded in $250 \mathrm{~Gy}$ and $350 \mathrm{~Gy}$. The maximum $\mathrm{CV}$ was recorded in $250 \mathrm{~Gy}$ (28.22) and lowest for $350 \mathrm{~Gy}$ (21.21) (Table 4).

El-Degwy et al., (2013) found result that higher dose mutagenic treatments decreased the mean values of secondary branches per panicle and lower dose of radiation detected 
significantly higher mean values. So, low doses of radiations in some cases stimulated the growth of $\mathrm{M}_{1}$ plants.

Total grain panicle ${ }^{-1}$ and filled grain per panicle $^{-1}$

Minimum and maximum mean values for Total grain panicle ${ }^{-1}$ in non-basmati aromatic rice varied from 350 Gy (136.77) to control (257.00). The highest (144.00-413.00) and lowest (90.00-199.00) range was recorded in control and $350 \mathrm{~Gy}$. The maximum $\mathrm{CV}$ was recorded in $250 \mathrm{~Gy}$ (22.89) and lowest for control (19.98) (Table 5).

Minimum and maximum mean values for Filled grain panicle ${ }^{-1}$ in non-basmati aromatic rice varied from 400 Gy (57.29) to control (196.98). The highest (87.00-326.00) and lowest (20.00-133.33) range was recorded in control and $400 \mathrm{~Gy}$. The maximum $\mathrm{CV}$ was recorded in 400 Gy (48.74) and lowest for control (24.21).

Table.1 Mean, range and coefficient of variation (CV) for plant height and panicle exsertion

\begin{tabular}{|l|l|l|l|l|l|l|}
\hline \multicolumn{4}{|c}{ Plant Height $(\mathbf{c m})$} & \multicolumn{3}{c|}{ Panicle Exsertion(cm) } \\
\hline Treatments & Mean & Range & CV & Mean & Range & CV \\
\hline Control & 153.27 & $136.00-172.00$ & 4.27 & 16.87 & $11.50-21.00$ & 11.26 \\
\hline 250 Gy & 144.69 & $127.00-177.00$ & 5.39 & 15.44 & $9.00-21.00$ & 16.05 \\
\hline 300 Gy & 145.24 & $128.30-170.20$ & 5.26 & 15.65 & $1.00-21.20$ & 23.57 \\
\hline $\mathbf{3 5 0}$ Gy & 140.24 & $117.00-160.00$ & 6.94 & 14.39 & $3.50-21.00$ & 35.12 \\
\hline $\mathbf{4 0 0}$ Gy & 136.26 & $116.00-158.00$ & 6.14 & 12.16 & $1.00-19.50$ & 36.58 \\
\hline
\end{tabular}

Table.2 Mean, range and coefficient of variation $(\mathrm{CV})$ for total tiller hill ${ }^{-1}$ and productive tiller hill $^{-1}$

\begin{tabular}{|l|l|l|l|l|l|l|}
\hline \multicolumn{4}{|c}{ Total tiller hill $^{-1}$} & \multicolumn{3}{c|}{ Productive tiller hill $^{-1}$} \\
\hline Treatments & Mean & Range & CV & Mean & Range & CV \\
\hline Control & 14.68 & $8.00-25.00$ & 25.27 & 13.30 & $7.00-23.00$ & 24.37 \\
\hline $\mathbf{2 5 0}$ Gy & 15.90 & $8.00-28.00$ & 29.90 & 12.68 & $7.00-24.00$ & 33.03 \\
\hline $\mathbf{3 0 0}$ Gy & 15.70 & $6.00-36.00$ & 37.07 & 10.45 & $3.00-22.00$ & 35.32 \\
\hline $\mathbf{3 5 0}$ Gy & 12.94 & $6.00-26.00$ & 36.96 & 7.42 & $3.00-16.00$ & 46.01 \\
\hline $\mathbf{4 0 0}$ Gy & 13.22 & $4.00-22.00$ & 37.31 & 9.78 & $2.00-21.00$ & 47.88 \\
\hline
\end{tabular}

Table.3 Mean, range and coefficient of variation $(\mathrm{CV})$ for flag leaf area $\left(\mathrm{cm}^{2}\right)$ and panicle length $(\mathrm{cm})$

\begin{tabular}{|c|c|c|c|c|c|c|}
\hline \multicolumn{4}{|c|}{ Flag leaf area $\left(\mathbf{c m}^{\mathbf{2}}\right)$} & \multicolumn{3}{c|}{ Panicle length $(\mathbf{c m})$} \\
\hline Treatments & Mean & Range & CV & Mean & Range & CV \\
\hline Control & 16.59 & $7.50-33.15$ & 29.28 & 27.26 & $19.00-32.00$ & 8.69 \\
\hline $\mathbf{2 5 0}$ Gy & 18.90 & $11.25-33.15$ & 25.93 & 26.23 & $21.00-29.50$ & 6.96 \\
\hline $\mathbf{3 0 0}$ Gy & 18.26 & $10.88-34.20$ & 23.40 & 25.68 & $18.00-29.60$ & 8.69 \\
\hline $\mathbf{3 5 0}$ Gy & 18.66 & $11.85-24.75$ & 17.58 & 25.50 & $20.00-29.00$ & 8.88 \\
\hline $\mathbf{4 0 0} \mathbf{~ G y}$ & 17.47 & $9.96-31.35$ & 27.22 & 25.21 & $10.00-31.00$ & 15.10 \\
\hline
\end{tabular}


Table.4 Mean, range and coefficient of variation $(\mathrm{CV})$ for primary branch panicle ${ }^{-1}$ and secondary branch panicle ${ }^{-1}$

\begin{tabular}{|c|c|c|c|c|c|c|}
\hline \multicolumn{4}{|c|}{ Primary branch panicle $^{-1}$} & \multicolumn{3}{c|}{ Secondary branch panicle } \\
\hline Treatments & Mean & Range & CV & Mean & Range & CV \\
\hline Control & 8.21 & $6.00-12.00$ & 15.75 & 27.44 & $15.00-53.00$ & 27.91 \\
\hline $\mathbf{2 5 0}$ Gy & 8.09 & $5.00-12.66$ & 17.06 & 25.47 & $12.33-55.33$ & 28.22 \\
\hline $\mathbf{3 0 0}$ Gy & 8.65 & $6.66-11.33$ & 11.75 & 28.90 & $14.66-51.00$ & 27.43 \\
\hline $\mathbf{3 5 0}$ Gy & 7.78 & $5.66-9.66$ & 13.02 & 24.05 & $13.33-34.00$ & 21.21 \\
\hline $\mathbf{4 0 0}$ Gy & 8.03 & $5.33-10.33$ & 14.46 & 25.53 & $13.66-47.00$ & 25.17 \\
\hline
\end{tabular}

Table.5 Mean, range and coefficient of variation (CV) for total grain per panicle and filled grain per panicle

\begin{tabular}{|c|c|c|c|c|c|c|}
\hline \multicolumn{4}{|c|}{ Total grain panicle $^{-\mathbf{1}}$} & \multicolumn{3}{c|}{ Filled grain panicle $^{-\mathbf{1}}$} \\
\hline Treatments & Mean & Range & CV & Mean & Range & CV \\
\hline Control & 257.00 & $144.00-$ & 19.98 & 196.98 & $87.00-326.00$ & 24.21 \\
& & 413.00 & & & & \\
\hline $\mathbf{2 5 0}$ Gy & 142.16 & $75.00-231.00$ & 22.89 & 76.25 & $18.34-155.33$ & 43.73 \\
\hline $\mathbf{3 0 0}$ Gy & 163.58 & $59.00-232.99$ & 22.40 & 85.47 & $26.66-185.33$ & 39.81 \\
\hline $\mathbf{3 5 0}$ Gy & 136.77 & $90.00-199.00$ & 20.41 & 64.63 & $27.00-170.33$ & 48.22 \\
\hline $\mathbf{4 0 0}$ Gy & 144.03 & $87.33-211.00$ & 20.59 & 57.29 & $20.00-133.33$ & 48.74 \\
\hline
\end{tabular}

Table.6 Mean, range and CV for spikelet fertility \% and yield panicle ${ }^{-1}(\mathrm{~g})$

\begin{tabular}{|c|c|c|c|c|c|c|}
\hline \multicolumn{4}{|c|}{ Spikelet Fertility \% } & \multicolumn{3}{c|}{ Yield panicle $^{-\mathbf{1}}(\mathbf{g})$} \\
\hline Treatments & Mean & Range & CV & Mean & Range & CV \\
\hline Control & 76.46 & $52.80-3.12$ & 11.99 & & $0.98-3.27$ & 31.07 \\
\hline $\mathbf{2 5 0}$ Gy & 53.83 & $10.89-93.08$ & 38.33 & 0.83 & $0.32-1.54$ & 39.16 \\
\hline $\mathbf{3 0 0}$ Gy & 53.25 & $25.72-96.17$ & 38.96 & 0.92 & $0.34-1.89$ & 37.64 \\
\hline $\mathbf{3 5 0}$ Gy & 47.38 & $20.20-85.59$ & 41.52 & 0.86 & $0.25-1.80$ & 48.90 \\
\hline $\mathbf{4 0 0}$ Gy & 39.35 & $0.76-88.07$ & 15.34 & 2.00 & $0.25-1.5$ & 48.27 \\
\hline
\end{tabular}

\section{Spikelet fertility \%}

Minimum and maximum mean values for Spikelet Fertility \% in non-basmati aromatic rice varied from 400 Gy (39.35) to control (76.46). The highest (0.76-88.07) and lowest (52.80-93.12) range was recorded in $400 \mathrm{~Gy}$ and control. The maximum $\mathrm{CV}$ was recorded in 350 Gy (41.52) and lowest for control (11.99) (Table 6).
Rajrajan et al., (2015) reported that in initial evaluation trial $\left(\mathrm{M}_{1}\right)$, the, pollen fertility, plant height at maturity, seed fertility showed a dose dependent reduction for the mutagens. Mutagenic treatments generally reduced the reproductive ability of plants and increased the number of sterile spikelets in panicle. Similar results were obtained in rice by Sasikala and Kalaiyarasi (2010) Singh et al., 1998. The decrease in fertility of rice after irradiation is considered to be due to 
chromosomal aberrations (Matsuo and Onozawa, 1961).

\section{Yield panicle $^{-1}(\mathrm{~g})$}

Minimum and maximum mean values for Yield per panicle $(\mathrm{g})$ in non-basmati aromatic rice varied from 250 Gy $(0.82)$ to control (2.00). The highest (0.98-3.27) and lowest (0.32-1.54) range was recorded in control and $250 \mathrm{~Gy}$. The maximum CV was recorded in $350 \mathrm{~Gy}$ (48.90) and lowest for control (31.07) (Table 6).

The magnitude of decline in mean coupled with high $\mathrm{CV}$ was more pronounced. Of the several traits, grain yield showed major drastic effects of the treatments. Similar results were also reported in different crops including rice by Tripathi and Dubey (1992).

The overall results indicated that spikelet fertility percentage $(\%)$ was more sensitive to gamma irradiation as compared to other yield attributing characters in non-basmati aromatic rice. Therefore, changes observed in quantitative characters in $\mathrm{M}_{1}$ generation need to be studies in $\mathrm{M}_{2}$ and later generations for understanding mutational changes in the genetic architecture of this important nonbasmati aromatic rice.

\section{References}

Bansal, V., Katoch P. C. and Plaha P. 1990. Mutagenic effectiveness of gamma rays, ethyl methane sulphonate and their combined treatments in rice. Crop Improvement. 17(1): 73-75

Chakraborty, N.R. and Kole, P.C. 2008. Biological effects of gamma rays on aromatic rice. Indian Journal of Crop Sciences. 3(1): 55-58.

Chakravarti, S.K., Singh, S., Kumar, H., Lal, J.P. and Vishwakarma, M.K. 2013. Induced mutation in traditional aromatic rice-Frequency and spectrum of viable mutations and characterizations of economic values. The Bioscan. 7(4): 739-742.

Cheema, A.A. and Atta, B.M. 2003. Radio sensitivity studies in Basmati rice. Pakistan Journal of Botany. 35: 197207.

Efendi, Bakhtiar, Zakaria, S., Hakim, L. and Sobrizal. 2017. Mutation with gamma ray irradiation to assemble green super rice tolerant to drought stress and high yield rice (Oryza sativa L.). International Journal of Advances in Science Engineering and Technology Vol-5(3): 1-5.

El-Degwy, I.S. 2013. Mutation induced genetic variability in rice (Oryza sativa L.). International Journal of Agriculture and Crop. 5(23): 27892794.

Harding, S.S., Johnson, D., Taylor, D.R., Dixon, C.A. and Turay, M.Y. 2012. Effect of Gamma Rays on Seed Germination, Seedling Height, Survival Percentage and Tiller Production in Some Rice Varieties Cultivated in Sierra Leone. American Journal of Experimental Agriculture. 2(2): 247-255.

Matsuo, T. and Onozawa, Y. 1961. Mutations induced in rice by ionizing radiations and chemicals. In: Effects of Ionizing Radiations on Seeds, IAEA, Vienna. pp. 495-501.

Pillai, M. A., Subramanian M. and Murugan S. 1993. Effectiveness and efficiency of gamma rays and EMS for chlorophyll mutants in upland rice. Annals of Agriculture Research. 14: 302-305

Rajarajan, D., Saraswathi, R., Sassikumar, D. and Ganesh, S.K. 2015. Studies on mutagenic effects of gamma rays and methyl sulfonate on $\mathrm{M}_{1}$ generation in 
ADT 47 rice. Life Sciences Leaflets. 60: 97-105.

Reddy T.V.V.S. and Rao D.R.M. 1988. Relative effectiveness and efficiency of single and combination treatments using gamma rays and sodium azide in inducing chlorophyll mutations in rice. Cytologia. 53: 491-498

Sasikala, R. and Kalaiyarasi, R. 2010. Sensitivity of rice varieties to gamma irradiation. Electronic Journal of Plant Breeding. 1(4): 885-889.

\section{How to cite this article:}

Zafar Imam and Nihar Ranjan Chakraborty. 2018. Effect of Gamma Rays on Non-basmati Aromatic Rice in $\mathrm{M}_{1}$ Generation. Int.J.Curr.Microbiol.App.Sci. 7(08): 4412-4418. doi: https://doi.org/10.20546/ijcmas.2018.708.464 